\section{Estudo histológico e ultra estrutural da mucosa do seio maxilar em pacientes com rinossinusite crônica e polipose nasossinusal}

\author{
João Vicente Dorgam¹, Bruno Beltrão de Souza', \\ Sabrina Maria de Castro Sarreta', Maria Dolores \\ Seabra Ferreira², Valder Rodrigues de $\mathrm{Melo}^{3}$, \\ WilmaT. Anselmo-Lima ${ }^{4}$
}

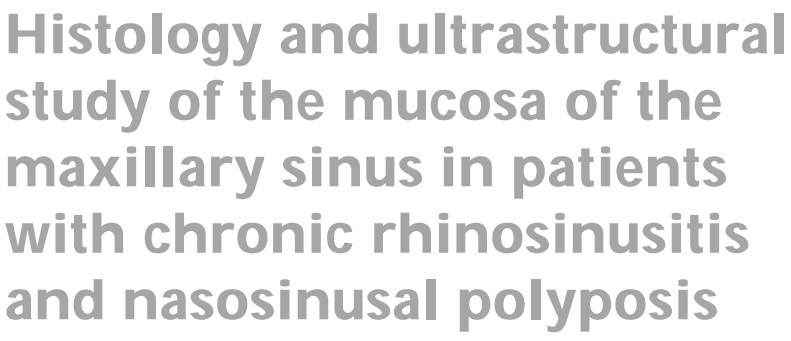

Resumo / Summary

$\mathbf{N}$ rinossinusite crônica, a inflamação da mucosa nasossinusal provoca alterações qualitativas e quantitativas do epitélio respiratório que recobre toda a cavidade nasossinusal, levando à manutenção do quadro inflamatório. Forma de estudo: Caso-controle. Material e método: Foram avaliados histopatologicamente dez pacientes com rinossinusite crônica (RC) e polipose nasossinusal (PN) por meio da história clínica e alérgica, estudo microbiológico, microscopia óptica, eletrônica de transmissão e varredura. Resultado: A diminuição do número de células colunares ciliadas, 0 aumento das células caliciformes, a diminuição do número de cílios por célula afetada e a metaplasia escamosa foram alterações freqüentemente encontradas nos casos de rinossinusite, explicando a persistência do quadro pela destruição no epitélio e quebra do sistema mucociliar.
Palavras-chave: rinossinusite crônica, mucosa, seio maxilar, alterações, ultraestrutural, histológico.

Key words: chronic rhinosinusitis, mucosa, maxillary sinus, ultrastructural, histologic. $\mathrm{n}$ chronic rhinosinusitis, inflammation of the rhinosinusal mucosa provokes qualitative and quantitative changes in the respiratory epithelium that lines the entire rhinosinusal cavity, leading to the maintenance of an inflammatory picture. Study design: Case-control. Material and method: In the present study we evaluated histopathologically ten patients with chronic rhinosinusitis on the basis of clinical and allergic history, microbiological study, and light, electron and scanning electron microscopy. Results: A reduced number of ciliated columnar cells, an increase in goblet-like cells, a reduction in the number of cilia per affected cell and squamous metaplasia were changes frequently detected in the cases of rhinosinusitis, explaining the persistence of the signs and symptoms due to the destruction of the epithelium and to the breakdown of the mucociliary system.

\footnotetext{
${ }^{1}$ Pós-Graduandos, Nível Mestrado do Departamento de Oftalmologia, Otorrinolaringologia e Cirurgia de Cabeça e Pescoço da FMRP-USP.

${ }^{2}$ Técnica do Laboratório de Microscopia Eletrônica do Biologia Celular e Molecular e Bioagentes Patogênicos.

${ }^{3}$ Professor Doutor do Departamento de Cirurgia e Anatomia da FMRP-USP.

${ }^{4}$ Professora Associada do Departamento de Oftalmologia, O torrinolaringologia e Cirurgia de Cabeça e Pescoço da FMRP-USP. Endereço para Correspondência: Profa. Dra. Wilma T. Anselmo-Lima - Departamento de O ftalmologia, Otorrinolaringologia e Cirurgia de Cabeça e Pescoço do HCFMRP-USP - Av.Bandeirantes, 3900 Ribeirão Preto SP 14049-900. Tel (0xx16) 602-2862 - Fax (0xx16) 602-2860.

Apresentado no II Congresso Triológico de Otorrinolaringologia da SBORL, Goiânia, 2001.

Artigo recebido em 10 de abril de 2003. Artigo aceito em 16 de outubro de 2003.
} 


\section{INTRODUÇÃO}

A Rinossinusite pode ser descrita, de modo geral, simplesmente como a inflamação da mucosa nasossinusal em resposta à ação de eventos infecciosos, traumáticos, exposição a químicos ou mesmo ação de alérgenos desencadeando um estado inflamatório da mucosa. Tal evento inicialmente tem características agudas que podem ser resolvidas espontaneamente ou por meio de ação de medicamentos que irão interagir para normalizar a mucosa do nariz e dos seios. Entretanto, em alguns casos, isso não ocorre e a persistência de tais alterações leva a um estado de cronificação.

A mucosa nasossinusal é especializada, conhecida em seu conjunto como revestida pelo epitélio respiratório, que é encontrado por todo o trato traqueobrônquico e também na orelha média. Tem em sua composição estruturas especializadas, como as células colunares ciliadas, as glândulas seromucosas, que, conjuntamente com as células caliciformes, irão produzir o muco, e todo o conjunto formará então o sistema mucociliar desse epitélio, importante mecanismo de defesa das vias aéreas. Q ualquer fal ha nesse sistema irá aumentar em muito a morbidade das estruturas dessas regiões, levando à instalação de processo inflamatório associado ou não à infecção ${ }^{1}$.

Portanto, o conhecimento das alterações que este epitélio sofre em processos de cronificação explica melhor a razão pela qual, em certos casos, existe uma facilitação da instalação de quadros inflamatórios resistentes a tratamentos clínicos ou cirúrgicos. Tais alterações podem estar relacionadas à incapacidade que a mucosa tem de manter seus mecanismos de defesa. Nosso objetivo foi estudar as principais alterações histológicas e ultraestruturais da mucosa do seio maxilar de pacientes com rinossinusite crônica e polipose nasossinusal submetidos à cirurgia endoscópica dos seios.

\section{CASUÍSTICA E MÉTODOS}

0 grupo de estudo foi composto de 10 pacientes atendidos no Ambulatório de Rinossinusologia do Departamento de O ftalmologia e O torrinolaringologia da Faculdade de Medicina de Ribeirão Preto da Universidade de São Paulo (FMRP-USP), com aprovação do Comitê de Ética em Pesquisa do H.C.R.P., de acordo com o processo no 1930/97.

Os pacientes foram submetidos à cirurgia endoscópica com diagnóstico de RC e PN rebelde a tratamentos clínicos antes instituídos, por meio da história clínica, nasofibroscopia e tomografia computadorizada de seios paranasais, apresentando alterações como: espessamento mucoso de seio maxilar, obliteração total ou parcial de complexo ostiomeatal e opacificação com densidade de partes moles.

No grupo de estudo $40 \%$ eram do sexo feminino e $60 \%$ do sexo masculino, com idades que variavam entre 11 e 73 anos.
Foram excluídos os pacientes com cirurgia nasal e/ ou paranasal anterior e portadores de afecções associadas, como fibrose cística, discinesia ciliar primária, imunodeficiência, intolerância ao ácido acetil salicílico e asma grave.

0 grupo controle foi composto de 4 cadáveres submetidos à necropsia pelo Serviço de Verificação de Ó bitos do Departamento de Patologia da FMRP-USP, sem história prévia de rinossinusite, e com causa mortis não infeciosa. Submetidos à nasofibroscopia, não apresentavam alterações anatômicas ou suspeitas de doença respiratória.

Foram solicitados os seguintes exames laborato riais pré-operatórios: hemograma completo, coagulograma e dosagem de IgE total, com o intuito de diferenciar possíveis pacientes alérgicos. Os testes cutâneos foram realizados no Departamento de Imunologia da FMRP-USP durante a internação cirúrgica do paciente.

A mucosa foi retirada durante 0 ato operatório da parede súpero-lateral da cavidade do seio maxilar. Foi utilizada uma pinça curva de Blakesley-Wilde, e a amostra tratada dentro de um metodo padronizado para se evitar a introdução de erros decorrentes do procedimento. Os seguintes passos foram feitos:

Fixação do fragmento em uma solução de aldeído glutárico a 3,0\% em tampão Sorensen por 3 a 4 horas. As amostras destinadas ao exame pela microscopia eletrônica de transmissão (MET) foram divididas em fragmentos ainda menores que, após serem lavados no tampão, foram imersos em uma solução de tetróxido de ósmio a 1,0\% em tampão Sorensen 0,1 Molar por 2 horas em temperatura de 4 graus Celsius. Desidratados, os fragmentos foram infiltrados e incluídos na Resina Araldite 6005, seccionados em um ultramicrótomo (Reichert UltraCut S) na espessura inicial de 0,5 micrômetro e montados em lâminas histológicas. Os cortes assim obtidos eram corados pela solução de azul de toluidina a 1,0\% em bórax e guardados para exame à microscopia óptica (MO). Feita a análise e seleção dos cortes dos fragmentos, os blocos eram reaparados e submetidos ao corte ultrafino (60-70 nanômetros), que eram recolhidos em grades de cobre, e submetidos a um processo de contrastação pelo acetato de uranila e citratato de chumbo, observados e eletronfotografados em um Microscópio Philips 208 operando a $80 \mathrm{Kv}$ em chapas Kodak 4489 em aumentos variáveis.

Os fragmentos destinados ao exame à microscopia eletrônica de varredura (MEV) permaneciam na solução de aldeído glutárico a 3,0\% por 3 horas, e eram lavados em tampão fosfato Sorensen para remoção do aldeído livre. Em seguida eram imersos em solução de tetróxido de ósmio a $1,0 \%$ em tampão fosfato 0,1 Molar em temperatura de 4 graus Celcius, desidratados em etanol e secados pelo ponto crítico em um CPD-030 BAL-TEC. As amostras foram então montadas nos suportes apropriados mediante o uso de uma pasta condutora (Conducting Graphite Paint/ Laad Research Industries), revestidas em ouro na unidade SCD-050 BAL- 
TEC, examinadas e eletronfotografadas em um microscópio de varredura JEO L JSM 5200 em aumentos variáveis, utilizando-se o filme Verichrome Pan Kodak VP 120.

Os cortes semifinos corados pelo azul de toluidina serviram de base para o estudo à MO. Com eles foi feita a classificação do tipo epitelial do revestimento mucoso baseado no número de camadas celulares (simples, estratificado ou pseudo-estratificado) e no tipo celular mais superficial (escamoso, colunar). Foram fotomicrografados em um fotomicroscópio Zeiss com objetivas Apo 40 ou PlaApo 63 em iluminação Kohler e filme Prolmage 100.

\section{RESULTADOS}

Foram estudados dez pacientes portadores de RC e $P N$. Cinco pacientes tinham queixas alérgicas ou antecedentes de doenças alérgicas na infância. Nenhum paciente tinha antecedentes familiares ligados à alergia ou doença sinusal semelhante. Os pacientes foram submetidos à dosagem de IgE total sérica, mas apenas seis apresentaram dados alterados acima do proposto como normal pelo Laboratório de Imunologia do HCFMRP-USP. Sete pacientes apresentaram positividade no teste cutâneo para alguns dos alérgenos testados (Tabela 1). Na classificação dos pacientes em grupos de alérgicos e não alérgicos foram usados três parâmetros: história alérgica, teste cutâneo e dosagem de IgE total. Os pacientes com história clínica positiva para alergia e positividade no teste cutâneo da pele foram considerados como pertencentes ao grupo alérgico.

No ato cirúrgico foram coletadas secreção e mucosa e enviadas para cultura de anaeróbios, aeróbios, micologia, realizada no Laboratório de Microbiologia do HCRP. Dos dez pacientes estudados, oito apresentaram positividade, sendo que havia sempre uma associação de dois ou mais microorganismos presentes. Os microorganismos encontrados nos oito pacientes com cultura positiva estão demonstrados na Tabela 2.

\section{Estudo histológico e ultra-estrutural}

O grupo controle, composto de quatro cadáveres, teve várias amostras de cada um exaustivamente estudadas às MO, MET e MEV. Todas apresentaram epitélio pseudoestratificado colunar ciliado (epitélio respiratório normal): mucosa fina com poucas células caliciformes, uma única camada do epitélio sobre uma membrana basal delicada. A lâmina própria, também fina, estava composta por tecido conjuntivo frouxo com leucócitos espalhados. A MEV mostrou uma superfície ciliar intensa e orientada, com os cílios apresentando aspecto morfológico normal (Figura 1).

0 grupo de estudo, composto de dez pacientes, teve suas amostras retiradas durante a cirurgia endoscópica realizada. Várias amostras de cada paciente foram da mesma forma estudadas. A distribuição dos epitélios encontrados está na Tabela 3. Dois pacientes apresentavam epitélio respiratório normal na sua superfície, mas, curiosamente, a lâmina própria não estava normal. Foram vistas áreas de processo inflamatório (com ausência de organização no interstício celular, presença de restos celulares disseminados, população celular composta principalmente de plasmócitos e macrófagos e áreas de processo inflamatório crônico, com fibrose da lâmina própria próxima ao epitélio, presença de elementos de destruição e limpeza, agressão intensa à mucosa, diversidade e abundância de figuras celulares. Dois pacientes apresentaram uma mucosa com epitélio respiratório atípico: uma diminuição importante no número de células ciliadas, com um aumento de células caliciformes por todo epitélio e extruindo na superfície; espaços intercelulares aumentados. As células basais ap resentavam um aspecto morfólogico diferente, estavam mais aplainadas e achatadas (Figura 2). A lâmina própria apresentava-se com áreas de intensa inflamação, com riqueza na diversidade celular, e às vezes com áreas de fibrose. Três pacientes apresentaram a mucosa com epitélio metaplásico. Em dois casos a camada de células mais achatadas era única, mas as células cuboidais exibiam grânulos de secreção; um caso com

Tabela 1. Pacientes portadores de RC + PNS submetidos à cirurgia. Apresentação dos casos em relação à história e exames complementares.

\begin{tabular}{|c|c|c|c|c|c|}
\hline Caso & Sexo & Idade & História de Alergia & Teste Cutâneo & Níveis de lgE total (UI/ml \\
\hline 1 & $M$ & 58 & - & + & 17 \\
\hline 2 & $M$ & 66 & + & - & 180 \\
\hline 3 & $M$ & 36 & + & + & 375 \\
\hline 4 & M & 73 & + & - & 2.272 \\
\hline 5 & $M$ & 11 & + & + & 1.904 \\
\hline 6 & $\mathbf{F}$ & 29 & - & + & 72 \\
\hline 7 & $M$ & 47 & + & - & 77 \\
\hline 8 & F & 17 & - & + & 3.515 \\
\hline 9 & $\mathbf{F}$ & 33 & + & + & 141 \\
\hline 10 & $\mathbf{F}$ & 35 & + & + & 53 \\
\hline
\end{tabular}

* Valor Normal: $100 \mathrm{UI} / \mathrm{ml}$ 
Tabela 2. Microorganismos encontrados nos oito pacientes que apresentaram cultura positiva

\begin{tabular}{ll}
\hline AERÓBIOS & $\mathbf{n}$ \\
Bacilo Gram (+) & 4 \\
Cocos Gram (+) & 3 \\
& \\
ANAE RÓBIOS & $\mathbf{n}$ \\
Streptococcus Grupo D & 2 \\
Eubacterium lentum & 3 \\
Peptostreptococcus species & 1 \\
Pseudomonas aeruginosa & 3 \\
Proteus vulgaris & 1 \\
\hline
\end{tabular}

$\mathrm{n}=$ número de culturas positivas epitélio estratificado escamoso, com espaços intercelulares bem aumentados (Figuras 3 e 4). A lâmina própria exibia uma rica diversidade celular, com áreas de processos inflamatórios agudo e crônico. Os últimos três pacientes apresentaram diferentes tipos epiteliais cobrindo a mucosa do seio maxilar: áreas de epitélio metaplásico entremeadas com áreas de epitélio respiratório total mente desprovido de cílios. Foram observados uma diminuição importante do número de células ciliadas, do número de cílios, e células com muitos grânulos de secreção na sua superfície apical (Figura 5). A lâmina própria apresentava áreas de processo inflamatório agudo e crônico.

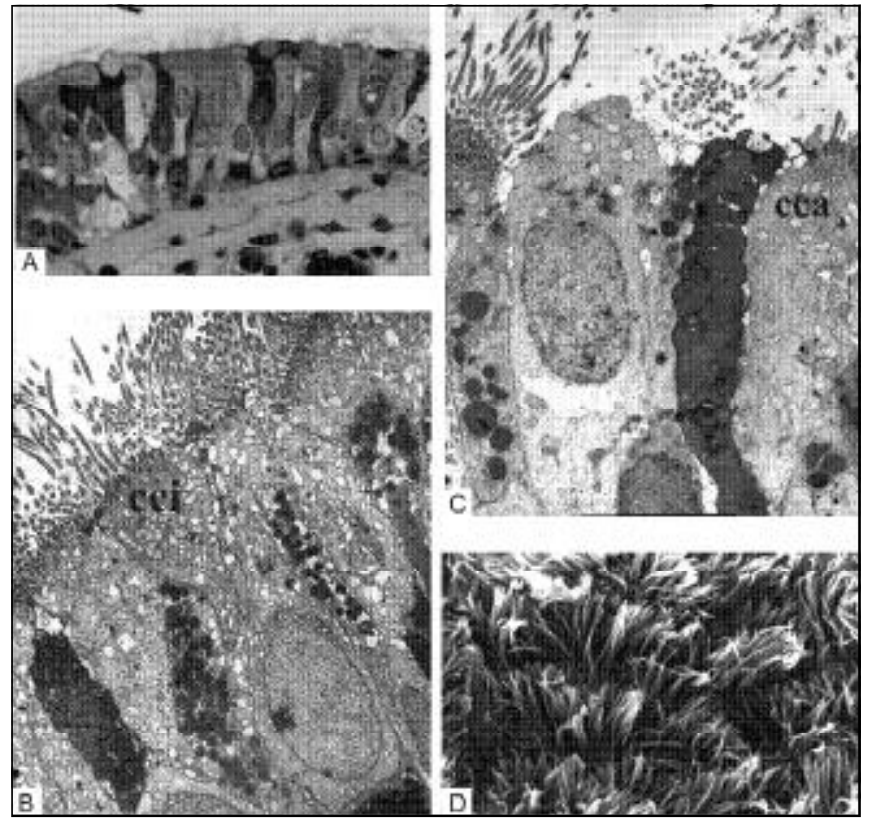

Figura 1. Epitélio respiratório normal encontrado no grupo controle (cadáveres). A- MO (63X); B- MET: células ciliadas entremeadas (cci) com células caliciformes (cca) (4.000X); C - MET: célula ciliada, célula não ciliada e célula caliciforme na superfície (4.000X); D- superfície ciliar normal à MEV (3.500X).

Tabela 3. Tipos de epitélios encontrados nos pacientes estudados.

\begin{tabular}{lc}
\hline Tipos de Epitélio & Número de Casos \\
\hline Epitélio Respiratório Normal & 2 \\
Epitélio Respiratório Atípico & 2 \\
Epitélio Metaplásico & 3 \\
Epitélio Misto & 3 \\
\hline
\end{tabular}

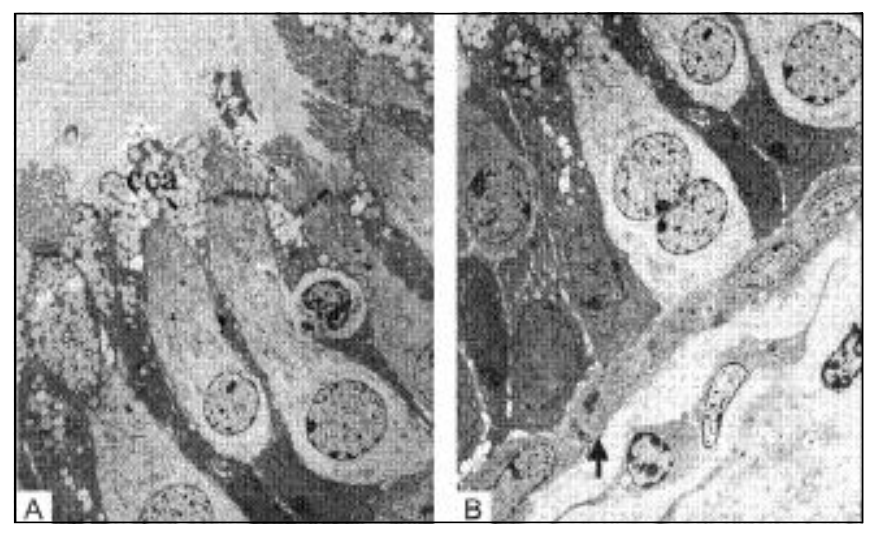

Figura 2. Pacientes A-MET: epitélio respiratório atípico: aumento de células caliciformes (cca) (2.000X); B - MET: células basais achatadas - seta (2.000X).

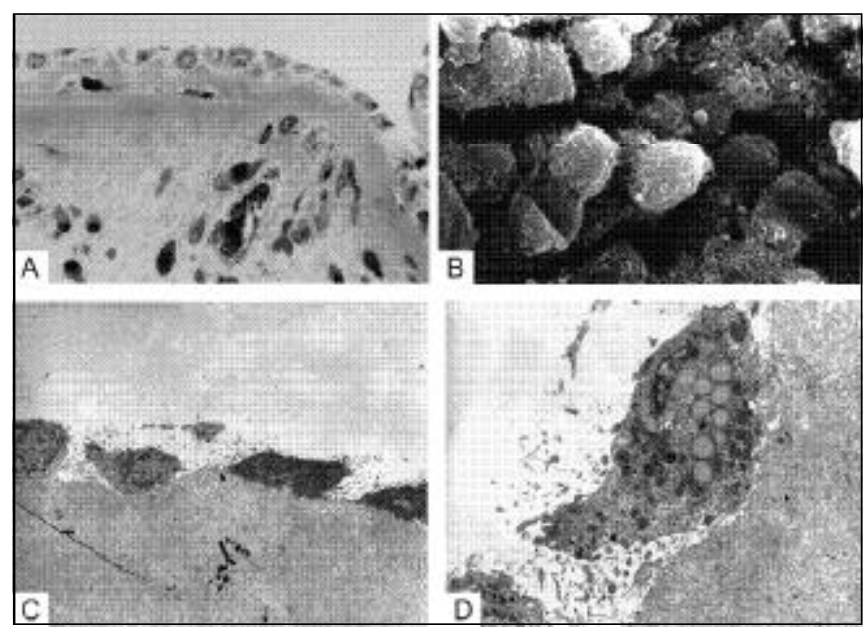

Figura 3. Pacientes - Epitélio metaplásico. A- MO (63X); B- MEV: células cuboidais do epitélio metaplásico pluriestratificado, ausência total de cílios (3.500X); C - MET: camada única de células achatadas, lâmina própria rica em fibrose (2.500X); D- MET: célula metaplásica plana rica em grânulos de secreção (8.000X). 


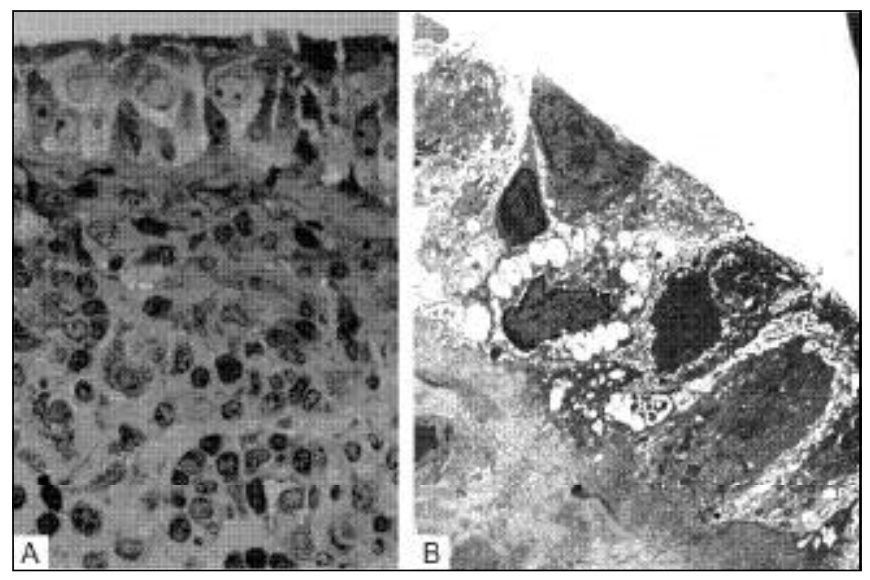

Figura 4. Pacientes - Epitélio metaplásico pluriestratificado. A- MO: lâmina própria ricamente inflamada (63X); B- MET: grandes espaços intercelulares (4.000X).

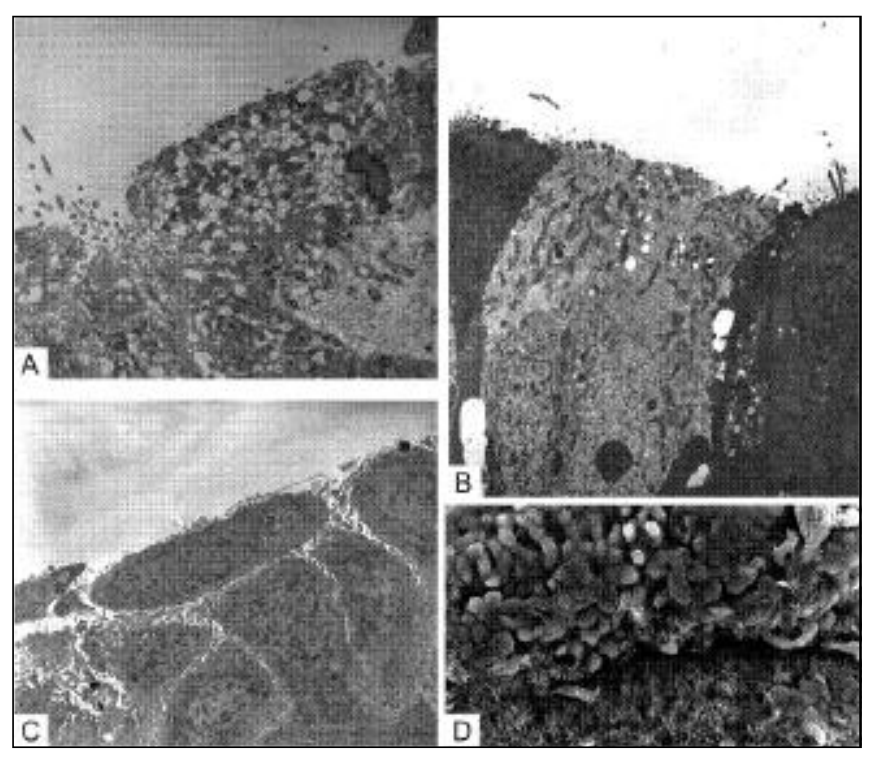

Figura 5. Pacientes - Epitélio misto. A- MET: célula epitelial da superfície com muitos grânulos de secreção (5.000X); B- MET: superfície epitelial desprovida de cílios (2.500X); C - MET: metaplasia escamosa (4.000X); D- MEV: área com metaplasia escamosa, células cuboidais, poucas células ciliadas, entremeadas com área de muitas células ciliadas (750X).

\section{DISCUSSÃO}

A inflamação da mucosa nasossinusal em quadros agudos ou crônicos vem sendo discutida na literatura otorrinolaringológica sob vários aspectos: quadros clínicos característicos, distribuição de idade, raça e sexo, história alérgica e doenças de base associadas, que facilitariam 0 desenvolvimento ou a manutenção da alteração da mucosa, tentando especificar possíveis grupos de maior incidência da afecção.
O s pacientes avaliados neste estudo tiveram na sua distribuição de faixa etária resultados compatíveis com os encontrados por Toskala et al. (1995)², média de 37 anos e Guo et al. (1997) ${ }^{3}$, média de 45 anos. No nosso estudo 40\% dos casos estavam entre 31 e 45 anos.

É interessante notar que nas três primeiras décadas os casos representaram apenas $30 \%$ do nosso estudo. Tal afecção (RC) é mais predominante a partir da terceira déca$d a$, fato este compatível com os estudos citados anteriormente. 0 nosso grupo de estudo é constituído de seis pacientes do sexo masculino, representando $60 \%$ do total. Tal resultado é semelhante ao encontrado no levantamento de Guo et al. (1997)³, porém não segue os resultados dos estudos de Toskala el al. (1997)4, Al Rawi et al. $(1998)^{5}$, onde 0 sexo feminino se sobressaiu com $75 \%$ e $56,5 \%$ dos casos, respectivamente. Desta forma, é difícil inferir sobre a incidência quanto à predominância pelo sexo já que o estudo foi realizado em amostra de pequena monta e existem controvérsias na literatura atual.

As principais queixas apresentadas foram referentes à obstrução nasal e secreção nasal representando $70 \%$ das queixas isoladamente ou mesmo associadas. Em proporção bem menor, com cerca de $30 \%$ das queixas, ficaram destacados os episódios caracterizados de cefaléia, espirros e prurido nasal. Estes dados são corroborados com o estudo e Gaffar et al. (1998)6 que descreve a congestão nasal crônica, rinorréia, cefaléia, tosse crônica e anosmia como queixas presentes nestes quadros. A obstrução nasal como uma das p rincipais causas é facilmente explicável, já que na nasofibroscopia, bem como no estudo radiológico, foi verificada a presença de aumento das conchas nasais associada ou não à degeneração da mucosa nasal, obliteração do complexo ostiomeatal, com presença de pólipos ou espessamento de mucosa. A secreção nasal foi por vezes explicada pela sua estase que ocorre associada à obstrução e à infecção.

\section{Antecedentes alérgicos}

Este ponto tem sido muito discutido na literatura. A controvérsia está na questão da alergia como causa ou componente principal no desenvolvimento da rinossinusite crônica ou na sua manutenção. No grupo de alérgicos, notamos que o estudo histopatológico apresentava diferentes tipos epiteliais em dois pacientes, epitélio cuboidal em um paciente, epitélio respiratório em dois pacientes. Em seis casos o epitélio se mostrou de secretor a altamente secretor e em apenas um caso apresentava-se não secretor com metaplasia. No grupo de pacientes que apresentava resposta alérgica aumentada, porém sem antecedente alérgico, encontramos epitélio atípico altamente secretor e epitélio misto secretor. Estes dados nos levam a relacionar a alergia ou a resposta alérgica como um dos fatores na manutenção dos quadros inflamatórios crônicos pelas alterações histopatoló gicas encontradas. Tal achado também foi evidente para alguns autores, que descreveram um infiltrado inflamatório marcante 
e alterações das características celulares do epitélio estudado, como o acréscimo populacional de células secretoras, diminuição das células ciliadas e mudanças estruturais do epitélio através da metaplasia celular escamosa ${ }^{7-10}$.

0 grupo de pacientes considerado não alérgico apresentou epitélio respiratório normal em dois casos e epitélio escamoso secretor em um caso, que apresentava IgE altamente elevada, porém, teste cutâneo negativo e antecedente alérgico não característico.

\section{Estudo microbiológico}

Um outro parâmetro importante para analisar conjuntamente as alterações histológicas foi a presença de infecção do seio estudado. Para tanto, foi coletada secreção presente no ato cirúrgico. Dos dez casos estudados apenas dois não apresentaram cultura positiva. 0 fato de nossa amostragem ter $80 \%$ dos casos com presença de processo infeccioso presente corrobora a tese da infecção super imposta ajudar na perpetuação do processo inflamatório. Junto com a infecção encontramos epitélios que variavam do normal à metaplasia. Além do epitélio ser altamente secretor, a estrutura variou entre colunar e escamosa.Tais fatos são concordantes com estudos já realizados, como de Toskala et $\mathrm{al}^{2}$ (1995), que estudaram pacientes com infecção aguda e crônica e verificaram que havia um acréscimo significativo de células não ciliadas.

\section{Estudo histopatológico}

Como existe ainda amplo debate sobre a importância da alergia na patogênese da RC, decidimos inicialmente separar os pacientes alérgicos e não alérgicos dentro de grupos e estudar possível correspondência com os tipos histopatológicos encontrados. Como nenhuma relação foi observada, resolvemos não ampliar a discussão.

Tem sido relatado por muitos autores, tanto em pesquisas experimentais em coelhos como em humanos, que infecção crônica causa espessamento de toda a camada mucosa. Na clínica, freqüentemente encontramos alterações polipóides dos mais variados graus ou espessamento da mucosa dos seios maxilares e etmoidais durante as cirurgias endoscópicas dos seios paranasais.

Reimer et al. (1978) ${ }^{11}$, estudando amostras da mucosa do seio maxilar com MEV, encontraram áreas de epitélio não ciliado em 12 pacientes com RC.

Ohashi \& Nakai $(1983)^{12}$, fazendo o mesmo estudo na mucosa do seio maxilar de pacientes com RC, observaram aumento significativo de células não ciliadas na mucosa infectada, assim como extrusão de células epiteliais, edema da membrana ciliada, metaplasia escamosa e alterações na formação e composição dos cílios. Invasão de células inflamatórias na lâmina própria também foi descrita.

Stierna \& Carlsöö (1990) ${ }^{10}$, estudando mucosa maxilar de pacientes com RC, encontraram áreas de hiperplasia de células caliciformes no epitélio respiratório de vários de- les, assim como metaplasia escamosa em outros, mas não especificaram nem quantificaram os casos. Descreveram ainda outros achados, como espessamento subepitelial, aumento no número de células inflamatórias na lâmina própria e ainda presença de fibrose.

Min et al., em 1993', também encontraram em seus estudos redução importante da superfície ciliada da mucosa infectada de coelhos, assim como distorção morfológica dos cílios.

Todas essas alterações morfológicas encontradas pelos autores são descritas, mas não quantificadas. Baseados na resposta inflamatória, a maioria dos autores distingue quatro tipos de quadros histológicos na RC: edematoso ou hiperplásico, infiltrativo ou granuloso, fibroso e misto ${ }^{13,14}$. Entretanto, vários tipos histológicos são encontrados freqüentemente em uma ou mais amostras da mesma mucosa.

Em nosso grupo de pacientes estudados encontramos quatro tipos histológicos epiteliais. Apesar de dois pacientes apresentarem a mucosa com revestimento normal (epitélio respiratório típico), a lâmina própria mostrava áreas infiltradas por processo inflamatório, às vezes com intensa fibrose; dois pacientes com epitélio respiratório atípico, onde se percebia claramente a substituição das células ciliadas por número aumentado de células caliciformes altamente secretoras; três pacientes com epitélio metaplásico. A pesar de serem células escamosas achatadas, eram compostas de muitos grânulos de secreção ou apresentavam aumento dos espaços intercelulares; os últimos três casos eram compostos de epitélio misto: metaplasia escamosa e áreas de epitélio respiratório, com diminuição do número de células ciliadas e do número de cílios nas células. 0 tipo histológico mais encontrado na lâmina própria foi o infiltrativo e o misto: áreas de processo inflamatório agudo se entremeavam com áreas de processo crônico, onde a fibrose predominava, com grande quantidade de colágeno no interstício. A diversidade celular encontrada foi rica (neutrófilos, monócitos, linfócitos, plasmócitos, mastócitos, eosinófilos), demonstrando a presença de muitas das células inflamatórias invadindo o epitélio. Nossos resultados são os mesmos relatados pelos autores acima, apesar da maioria estudar mucosa de coelhos.

Muitos trabalhos relataram aumento importante no número de células caliciformes na inflamação crônica do seio maxilar10,15. Entretanto, exame histológico quantitativo da mucosa do seio maxilar realizado por Tos \& Morgensen, em $1984^{16}$, apontou diminuição importante da densidade de células caliciformes na RC. Segundo os autores, a mucosa polipóide e a necrose epitelial, que ocorrem num estágio mais precoce da doença (como parte do processo de regeneração, tornando-se coberta por nova camada epitelial relativamente jovem, com menor densidade de células caliciformes), poderiam explicar essa diferença. Encontramos em nossa casuística dois casos com hiperplasia de células caliciformes. Todos os outros apresentavam pequena quantidade delas. 
Verificamos espessamento subepitelial muitas vezes associado com número aumentado de células inflamatórias. Esse espessamento tem sido interp retado como hialinização da membrana basal (Nostrand \& Goodman, 1976) ${ }^{17}$, devendo prejudicar o transporte de fluidos, nutrientes e fatores protetores através do epitélio, reduzindo a capacidade da mucosa de resistir ao estresse microbiológico subseqüente e sem condições para auto-reparo pós-inflamação ${ }^{10}$. Metaplasia e extrusão de células epiteliais, por nós observadas, também têm sido relatadas por outros autores ${ }^{2,12}$, sendo provavelmente causadas por infecção, ataque virótico ou bacteriano.

Apesar de nossos pacientes desse grupo terem sido submetidos também à MET e MEV, não encontramos alterações ultra-estruturais no aspecto morfológico dos cílios como encontraram outros autores ${ }^{8,12}$.

Como demonstrado nesse estudo e pelos autores citados, inflamação crônica do seio maxilar pode resultar em perda importante da mucosa ciliada, com o desenvolvimento de epitélio respiratório atípico, metaplásico ou misto. Tais alterações devem estar associadas com anormalidades na função dos seios paranasais.

Segundo Kaliner et al. (1997) ${ }^{18}$ alterações na função epitelial podem ter papel importante na patogênese da RC, não somente pelas alterações morfológicas descritas, mas principalmente pela produção alterada de catabolitos epiteliais, que poderiam ter papel na inflamação celular. Células epiteliais são capazes de produzir citocinas e fatores estimulantes de colônias de granulócitos - macrófagos. Produção alterada de tais citocinas afetaria o recrutamento, a sobrevivência e o estado de ativação de leucócitos inflamados. Além do mais, produção alterada de óxido nítrico pelo epitélio poderia ser importante na capacidade de proteção antibacteriana. Recentemente, demonstrou-se que o óxido nítrico é produzido em grandes quantidades pelo epitélio sinusal humano saudável ${ }^{19}$. Devido a suas propriedades antivirais e bacteriostáticas, tem sido sugerido para o óxido nítrico papel na defesa do hospedeiro sinusal.

Baseados nessas observações, Kaliner et al. (1997) ${ }^{18}$ sugeriram que a inflamação é influenciada pelas alterações da função epitelial, e que ambas, afetadas por produtos bacterianos, poderiam perpetuar o ciclo inflamatório.

Apesar dos dados acumulados até o momento no que concerne a fatores precipitantes e perpetuadores da RC (elementos celulares críticos, citocininas e mediadores envolvidos, bactérias, vírus, organismos fúngicos ou produtos microbianos) pesquisas são necessárias para melhor entendimento da importância e maneira de atuar destes fatores no desencadeamento do processo inflamatório.

\section{CONCLUSÃO}

A inflamação crônica do seio maxilar pode resultar em uma importante modificação da cobertura epitelial da parede do seio maxilar com desenvolvimento de epitélio atípico, podendo chegar a casos de metaplasia.

\section{REFERÊNCIASBIBLIOGRÁFICAS}

1. Demarco RC, Anselmo-Lima WT. Fisiologia Nasal. In: Campos CAHC, Costa HOO. Tratado de Otorrinolaringologia. 1a Edição. V. 3. São Paulo: Editora Roca; 2002. p. 627-39.

2. Toskala E, Nuutinen J, Rautiainen M. Scanning Electron Microscopy Findings Of Human Respiratory Cilia. In: Chronic Sinusitis And In Recurrent Respiratory Infections. The Journal of Laryngology and O tology 1995; 109:509-14.

3. Guo Y, Majima Y, Hattori M, Seki S, Sakakura Y. Effects Of Functional Endoscopic Sinus Surgery On Maxillary Sinus Mucosa. Arch Otolaryngol Head Neck Surg 1997; 123:1097-100.

4. Toskala E, Westrin KM, Stierna P, Rautiainen M. Ciliary Ultrastructure In Experimental Sinusitis. Acta Otolaryngol Suppl (Stock) 1997; 529:137-9.

5. Al-Rawi MM, Edelstein DR, Erlandson RA. Changes In Nasal Epithelium In Patients With Severe Chronic Sinusitis: A Clinicopathologic And Electron Microscopic Study. Laryngoscope 1998; 108:1816-23.

6. Ghaffar O, Lavigne F, Kamil A, Renzi P. Interlenkin-6 expression in chronic sinusitis: colonization of gene transcripts to eosinophils macrophages lymphocytes and mast cells. Otolaryngol Head Neck Surg 1998; 118:504-11.

7. Westrin KM, Stierna P, Carlsöö, Hellström S. Mucosal Fine Structure in Experimental Sinusitis. Ann Otol Rhinol Laryngol 1993; 102(8):639-45.

8. Min YG, Lee $Y M$, Jung $H W$ et al. The effect of Ostial Opening on Experimental Maxillary Sinusitis in Rabbits. Rhinology 1993; 31:101-5.

9. Fukami M, Norlander T, Stierna $P$ et al. Mucosa pathology of the nose and sinuses: a study in experimental maxillary sinusitis in rabbits induced by Streptococcus pneumoniae Bacteroides fragilis and Staphylococcus aureus. Am J Rhinol 1993; 7: 125-32.

10. Stierna $P$, Carlsöö B. Histopathological observations in chronic maxillary sinusitis. Acta Otolaryngol (Stockh) 1990; 110:450-8.

11. Reimer A, von Mecklenburg C, Toremalm NG. The mucociliary activity of the upper respiratory tract III A functional and morphological study on human and animal material with special reference to maxillary sinus disease Acta Otolaryngol (Stockholm) 1978; 355(suppl):1-20.

12. Ohashi Y, Nakai Y. Fuctional and Morphological Pathology of Chronic Sinusitis Mucous Membrane. Acta Otorhinolaryngol 1983; 397:11-48.

13. Schall LRA. The histology and chronic inflammation of the nasal mucous membrane. Ann Otol Rhinol Laryngol 1933; 42:15-38.

14. Mann W, Trong HD. Vergleichende endoskipische und histologische Befunde bei chronischer Sinusitis. HNO 1979; 27:3457.

15. Albergger $\mathrm{KW}$. Abnormal hair like filaments in chronic maxillary sinusitis. Acta Otolaryngol 1978; 220: 239-49.

16. Tos M, Morgensen C. Mucus Production In Chronic Maxillary Sinusitis. A Quantitative Histopathological study. Acta Otolaryngol (Stockh) 1984; 97: 115-9.

17. Nostrand Van AWP, Goodman WS. Pathologic aspects of mucosal lesions of the maxillary sinus In: Noyek AM, Zizmor J eds Vol 9(1): The otolaryngologic clinics of North America. Symposium on the maxillary sinus. Philadelphia, London, Toronto: WB Saunders 1976; p.21-34.

18. Kaliner MA, Osguthorpe JD, Fireman P, Kennedy D. Sinusitis: bench to bedside Current findings future directions. Otolaryngol Head Neck Surg 19976 (suppl 116):1-19.

19. Lundberg JO, Farkas-Szallasi T, Weitzberg E. High nitic oxide in human paranasal sinuses Nat Med 1995 1:370-3. 